\title{
The Asymmetric Graetz Problem: The Analytical Solution Revisited
}

\author{
Seyed Sepehr Mohaddes Foroushani ${ }^{1}$ and John L. Wright ${ }^{2}$ \\ University of Waterloo, Waterloo, ON, N2L 3G1, Canada \\ and \\ David Naylor ${ }^{3}$ \\ Ryerson University, Toronto, ON, M5B 2K3, Canada
}

\begin{abstract}
Please note that this file contains the final draft version of this technical paper. Minor differences will be found between this version and the final version printed by the publisher. The reader should contact the publisher if the final version, as printed, is preferred.
\end{abstract}

Copyright $(\mathcal{C} 2016$ by the American Institute of Aeronautics and Astronautics, Inc. All rights reserved. Copies of this paper may be made for personal and internal use, on condition that the copier pay the per-copy fee to the Copyright Clearance Center (CCC). All requests for copying and permission to reprint should be submitted to CCC at www.copyright.com; employ the ISSN 0887-8722 (print) or 1533-6808 (online) to initiate your request.

Foroushani, S. S. M., Wright, J. L., \& Naylor, D. (2017). Asymmetric Graetz Problem: The Analytical Solution Revisited. Journal of Thermophysics and Heat Transfer, 31(1), 237-242. https://doi.org/10.2514/1.T4944

\footnotetext{
${ }^{1} \mathrm{PhD}$ Candidate, Department of Mechanical \& Mechatronics Engineering

${ }^{2}$ Professor, Department of Mechanical \& Mechatronics Engineering

${ }^{3}$ Professor, Department of Mechanical \& Industrial Engineering
} 


\title{
The Asymmetric Graetz Problem: The Analytical Solution Revisited
}

\author{
Seyed Sepehr Mohaddes Foroushani ${ }^{4}$ and John L. Wright ${ }^{5}$ \\ University of Waterloo, Waterloo, ON, N2L 3G1, Canada \\ and \\ David Naylor ${ }^{6}$ \\ Ryerson University, Toronto, ON, M5B 2K3, Canada
}

Forced-convective heat transfer from the walls of an asymmetrically-heated channel to the fluid passing through in a laminar, hydrodynamically-developed flow is known as the asymmetric Graetz problem. Several analytical and numerical solutions for this problem have been published and many variations and extensions have been investigated. Recently, there has been a renewed interest in this problem due to its applications in emerging areas such as microchannels and fuel cells. In the present work, the asymmetric Graetz problem is examined in a resistor-network framework. The formulation of the problem in terms of three convective resistances forming a delta network leads to temperature-independent Nusselt numbers that are free of the singularities found in previous results. The proposed approach also offers new information regarding the split of heat transfer between the channel walls and the flow. This work is part of an ongoing project on resistor-network modeling and characterization of multi-temperature convection problems.

\section{Nomenclature}

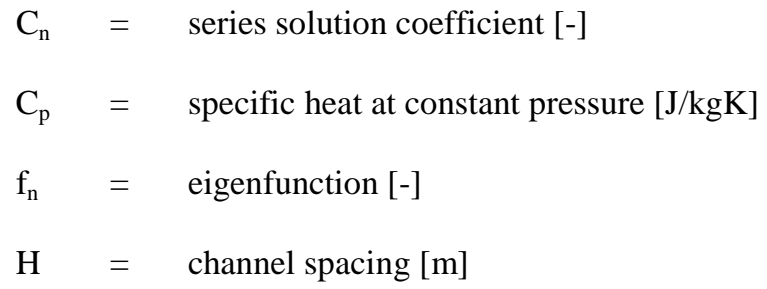

\footnotetext{
${ }^{4} \mathrm{PhD}$ Candidate, Department of Mechanical \& Mechatronics Engineering

${ }^{5}$ Professor, Department of Mechanical \& Mechatronics Engineering

${ }^{6}$ Professor, Department of Mechanical \& Industrial Engineering
} 


$$
\begin{aligned}
& \mathrm{k}=\text { thermal conductivity }[\mathrm{W} / \mathrm{mK}] \\
& \mathrm{Nu}=\text { local Nusselt number [-] } \\
& \overline{\mathrm{Nu}}=\text { average Nusselt number [-] } \\
& \operatorname{Pr} \quad=\quad \text { Prandtl number [-] } \\
& \mathrm{q}=\text { heat flux }\left[\mathrm{W} / \mathrm{m}^{2}\right] \\
& \mathrm{Q}=\text { heat transfer rate (per unit width) }[\mathrm{W} / \mathrm{m}] \\
& \mathrm{r}_{\mathrm{T}} \quad=\quad \text { temperature ratio (Eq. 1) [-] } \\
& \mathrm{R}=\text { (unit-width) thermal resistance [mK/W] } \\
& \operatorname{Re} \quad=\quad \text { Reynolds number (Eq. 3) [-] } \\
& \mathrm{T}=\text { Temperature [K] } \\
& \mathrm{x}=\text { flow-wise coordinate }[\mathrm{m}] \\
& \mathrm{X}=\text { inverse Graetz number (Eq. 3) [-] } \\
& \mathrm{y}=\text { coordinate perpendicular to walls [m] } \\
& \overline{\mathrm{y}} \quad=\quad \text { dimensionless } \mathrm{y} \text {-coordinate [-] }
\end{aligned}
$$

Greek Symbols

$$
\begin{aligned}
\theta & =\text { dimensionless temperature }[-] \\
\lambda_{\mathrm{n}} & =\text { eigenvalue }[-] \\
\mu & =\text { dynamic viscosity }[\mathrm{kg} / \mathrm{ms}] \\
\rho & =\text { density }\left[\mathrm{kg} / \mathrm{m}^{3}\right]
\end{aligned}
$$

Subscripts

$$
\begin{aligned}
& 0=\text { fluid at the inlet } \\
& 1 \quad=\text { upper wall } \\
& 2 \quad=\text { lower wall } \\
& \mathrm{i}=\text { at node } \mathrm{i} \\
& \mathrm{ij}=\text { paired: from node } \mathrm{i} \text { to node } \mathrm{j} \\
& \mathrm{m} \quad=\text { bulk (mean) value } \\
& \mathrm{wm}=\text { wall mean }
\end{aligned}
$$




\section{Introduction}

$A^{\text {Laminar, hydrodynamically-developed flow at temperature } T_{0} \text { enters the channel formed between two semi- }}$ infinite parallel plates maintained at temperatures $T_{1}$ and $T_{2}$. The plates are spaced at distance $H$. See Figure 1. The fluid properties $\left(\mathrm{k}, \rho, \mu, \mathrm{C}_{\mathrm{p}}\right)$ are assumed to be constant. The problem of computing the heat transfer between the channel walls and the fluid is known as the asymmetric Graetz problem.

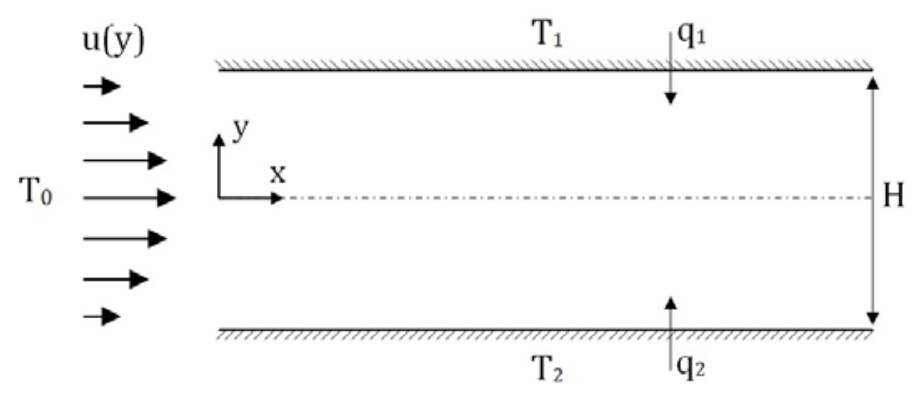

Fig. 1 Schematic of hydrodynamically developed flow in an asymmetrically-heated channel.

This is a three-temperature problem, i.e. it involves three isothermal sources: the two channel walls and the flow inlet. It is therefore convenient to define a temperature ratio; a constant, $r_{T}$, to specify the ordering of $T_{0}, T_{1}$ and $T_{2}$ - particularly the placement of $\mathrm{T}_{0}$ relative to $\mathrm{T}_{1}$ and $\mathrm{T}_{2}$. Equation 1 shows a common definition.

$$
\mathrm{r}_{\mathrm{T}}=\frac{\mathrm{T}_{0}-\mathrm{T}_{\mathrm{wm}}}{\mathrm{T}_{1}-\mathrm{T}_{\mathrm{wm}}}
$$

In Equation 1, $\mathrm{T}_{\mathrm{wm}}$ is the wall-mean temperature, a constant: $\mathrm{T}_{\mathrm{wm}}=\frac{\mathrm{T}_{1}+\mathrm{T}_{2}}{2}$.

It is helpful to visualize the evolution of the temperature profile and bulk fluid temperature, $T_{m}$, along the channel. See Figure 2, for example. At the entrance the fluid temperature is uniform: $T(x=0)=T_{0}$. Moving downstream, due to heat transfer from the walls the temperature profile evolves approaching a linear profile at $x \rightarrow \infty$. The variation of heat flux, $\mathrm{q}_{1}$ and $\mathrm{q}_{2}$, can be judged by examining the temperature gradient, $\frac{\partial \mathrm{T}}{\partial \mathrm{y}}$, at the walls. In the thermally fully developed limit, (a) the temperature profile becomes linear with $\lim _{\mathrm{x} \rightarrow \infty} \frac{\partial \mathrm{T}}{\partial \mathrm{y}}=\frac{\mathrm{T}_{1}-\mathrm{T}_{2}}{\mathrm{H}}$, (b) $\lim _{x \rightarrow \infty} T_{m}=T_{w m}$, and (c) the net heat flux to the fluid decays to zero, i.e., $\lim _{x \rightarrow \infty}\left(q_{1}+q_{2}\right)=0$ because 
$\lim _{\mathrm{x} \rightarrow \infty}\left(\mathrm{q}_{1}\right)=\lim _{\mathrm{x} \rightarrow \infty}\left(-\mathrm{q}_{2}\right)=\frac{\mathrm{k}}{\mathrm{H}}\left(\mathrm{T}_{1}-\mathrm{T}_{2}\right)$. Attention is usually focussed on the thermal entry length because this is where the net heat transfer to the fluid takes place; where the temperature profile is developing.

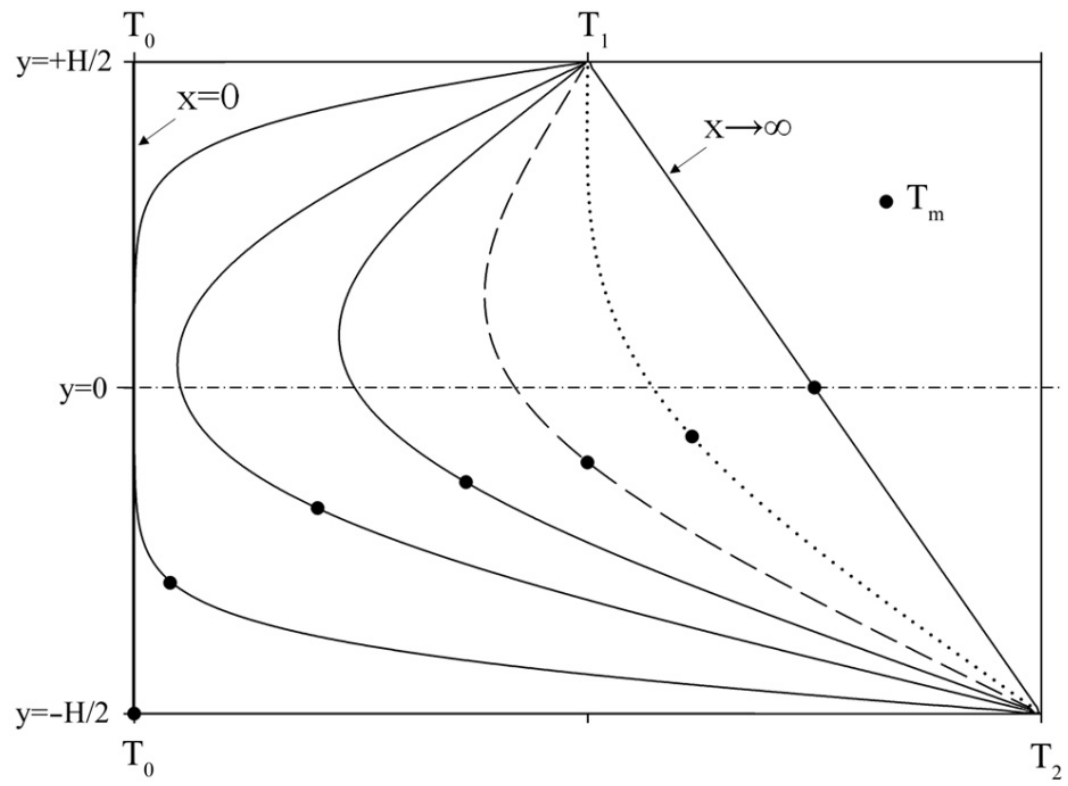

Fig. 2 Evolution of temperature profile and bulk fluid temperature $\left(T_{m}\right)$ in an infinitely long channel $\left(r_{T}=3\right)$.

Heat transfer in asymmetrically-heated channels has been extensively investigated. Many variations and extensions have been studied and several solutions, some analytical and some numerical, have been published. In recent years, the asymmetric Graetz problem has seen a renewed interest from researchers in emerging areas such as microchannels and fuel cells. The analytical solution by Hatton and Turton [1] is of particular interest to the present work.

With constant fluid properties, negligible conduction in the x-direction and negligible viscous dissipation, the energy balance at any location in the fluid is given by Equation 2 .

$$
\operatorname{puC}_{\mathrm{p}} \frac{\partial \mathrm{T}}{\partial \mathrm{x}}=\mathrm{k} \frac{\partial^{2} \mathrm{~T}}{\partial \mathrm{y}^{2}} \quad ; \quad \mathrm{u}=\frac{3}{2} \mathrm{u}_{\mathrm{m}}\left(1-\left(\frac{2 \mathrm{y}}{\mathrm{H}}\right)^{2}\right)
$$

Hatton and Turton [1] generated an analytical solution for the temperature field by applying separation of variables, reducing Equation 2 to a Sturm-Liouville system, the first eight eigenvalues of which were computed numerically. Hatton and Turton then used $\mathrm{T}(\mathrm{x}, \mathrm{y})$ to obtain series expressions for $\mathrm{q}_{1}, \mathrm{q}_{2}$ and $\mathrm{T}_{\mathrm{m}}$ - each in 
dimensionless form a function of the inverse Graetz number, $\mathrm{X}$, only. Equation 3 provides the definition of $\mathrm{X}$ in accordance with Hatton and Turton [1].

$$
\mathrm{X}=\frac{2 \mathrm{x}}{\mathrm{H}} \cdot \frac{1}{\operatorname{Re} \cdot \operatorname{Pr}} \quad ; \quad \operatorname{Re}=\frac{\rho \mathrm{u}_{\mathrm{m}}(2 \mathrm{H})}{\mu}, \quad \operatorname{Pr}=\frac{\mu \mathrm{C}_{\mathrm{p}}}{\mathrm{k}}
$$

Hatton and Turton presented their results in terms of local Nusselt numbers, $\mathrm{Nu}_{1}$ and $\mathrm{Nu}_{2}$, based on wall heat flux and the difference between the wall temperature and the mean fluid temperature, as defined in Equation 4.

$$
\mathrm{q}_{\mathrm{i}}=\mathrm{Nu}_{\mathrm{i}} \frac{\mathrm{k}}{2 \mathrm{H}} \cdot\left(\mathrm{T}_{\mathrm{i}}-\mathrm{T}_{\mathrm{m}}\right) \quad \mathrm{i}=1,2
$$

In Figure 3, a plot of $\left\{\mathrm{Nu}_{\mathrm{i}}\right\}$ for $\left\{\mathrm{r}_{\mathrm{T}}\right\}=\{0,1,2,3\}$ is reproduced from Hatton and Turton [1]. Two significant observations can be made about Figure 3. First, even though $\mathrm{q}_{1}$ is both continuous and finite for all $\mathrm{X}>0$, $\mathrm{Nu}_{1}$ has an extra singularity if $r_{T}>1$. This extra singularity arises because the driving temperature difference used to define $\mathrm{Nu}_{\mathrm{i}}$ (Equation 4) is based on $\mathrm{T}_{\mathrm{m}}$. For example, when $\mathrm{T}_{0}<\mathrm{T}_{1}<\mathrm{T}_{2}$ (as shown in Figure 2) $\mathrm{Nu}_{1}$ becomes indefinite in the location where $\mathrm{T}_{\mathrm{m}}=\mathrm{T}_{1}$. Moreover, $\mathrm{Nu}_{1}$ changes sign through this singularity, which is non-physical; $\mathrm{q}_{1}$ does not change sign until the temperature gradient normal to the wall becomes zero, i.e. at a local adiabatic point where $\mathrm{Nu}_{1}=0$. As shown by Mitrovic et al. [2], the singularity point, where $\mathrm{T}_{\mathrm{m}}=\mathrm{T}_{1}$ (dotted curve in Figure 2), is distinct from the local adiabatic point (dashed curve). Nield [3] asserted that the singularities seen in Figure 3 reduce the utility of the results. To address this deficiency, Nield [3] proposed a Nusselt number based on $\left(\mathrm{q}_{1}+\mathrm{q}_{2}\right)$ and $\left(\mathrm{T}_{\mathrm{wm}}{ }^{-}\right.$ $\left.T_{m}\right)$. The heat flux to the fluid, $\left(q_{1}+q_{2}\right)$, and the driving temperature difference, $\left(T_{w m}-T_{m}\right)$, both decay to zero as the flow becomes thermally developed, and the sense of each remains unchanged in the process. Accordingly, the extra singularity does not arise.

The second, and more important, observation about the results of Hatton and Turton is that $\left\{\mathrm{Nu}_{\mathrm{i}}\right\}$ depends on $\mathrm{r}_{\mathrm{T}}$. This is unexpected. Recall that in the case of a two-temperature forced-convection problem, e.g. flow in a symmetrically heated channel, the Nusselt number can be expressed as $\mathrm{Nu}=\mathrm{Nu}(\mathrm{Re}, \mathrm{Pr})$. Given that the only difference between the three-temperature and two-temperature cases is an additional non-homogenous (but linear) boundary condition, the nature of the solutions should be the same. In other words, it is expected that in the case of a three-temperature problem too, the solution could be expressed in terms of Nusselt number(s) that are independent of $\mathrm{r}_{\mathrm{T}}$. The results of Hatton and Turton exhibit this feature only in the thermally developed limit: $\lim _{X \rightarrow \infty} \mathrm{Nu}_{1}=\lim _{\mathrm{X} \rightarrow \infty} \mathrm{Nu}_{2}=4$. Nield [3] showed that in the thermally fully developed limit, the modified Nusselt number 
based on $\left(\mathrm{q}_{1}+\mathrm{q}_{2}\right)$ and $\left(\mathrm{T}_{\mathrm{wm}}-\mathrm{T}_{\mathrm{m}}\right)$ is not influenced by asymmetry $\left(\mathrm{r}_{\mathrm{T}}\right)$. The dependence on $\mathrm{r}_{\mathrm{T}}$ causes another problem: the solution cannot predict the limiting two-temperature case. According to Equation 1, $\mathrm{r}_{\mathrm{T}}$ becomes indefinite if $\mathrm{T}_{1}=\mathrm{T}_{2}$, causing another singularity in the solution. But as demonstrated by Nield [3], a properly defined Nusselt number would be identical for asymmetric and symmetric cases. Figure 3 might also lead to the conclusion that thermal development length of the flow is a function of $\mathrm{r}_{\mathrm{T}}$; this is not the case.

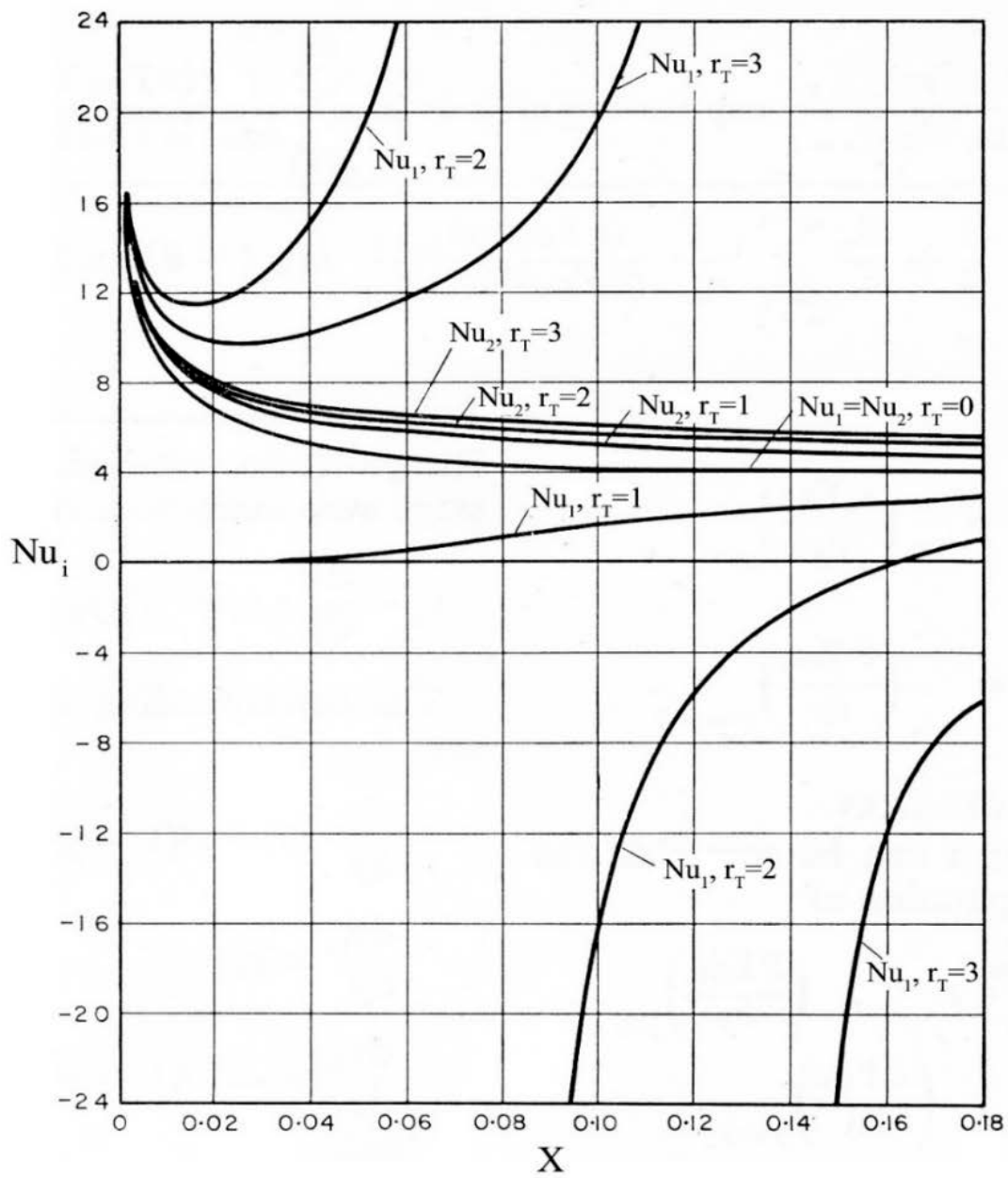

Fig. 3 Variation of local Nusselt numbers from the solution by Hatton and Turton [1] (reproduced with permission, labels altered to match current nomenclature).

In the work presented here the asymmetric Graetz problem is examined from a different perspective, using a resistor-network framework. Formulating the asymmetric Graetz problem in terms of a thermal-resistor network, the information presented in Figure 3 can be recast into a compact, simpler, but more generic format. This approach leads to a simpler representation of the benchmark solution of Hatton and Turton; addresses the shortcomings 
discussed above; yields Nusselt numbers that are independent of $r_{T}$ even in the thermal development region; is consistent with the physics of the problem; and provides more detail about the heat transfer at each wall.

It should be mentioned that the motivation behind this work is the desire to formulate steady-state heat transfer problems in terms of thermal-resistor networks. The resistor-network approach has significant computational advantages in the modeling of thermal phenomena, e.g. modeling heat transfer in windows for building energy simulation [4-6]. This paper demonstrates the formulation of a simple three-temperature convection problem in terms of a delta thermal-resistor network and presents a method for calculating the individual convective resistances of the network. The asymmetric Graetz problem was chosen as an example three-temperature convection problem due to the availability of an analytical solution. This work is part of an ongoing project on the modeling and characterization of multi-temperature convection problems encountered in building energy simulation in terms of resistor networks.

\section{The Resistor-Network Formulation of the Problem}

The heat transfer rate at a wall from the channel entrance to any point, $Q_{i}$, is influenced by the three independent temperatures involved, i.e. the temperature boundary conditions $\left\{T_{i}\right\}$. More specifically, extending the traditional approach of formulating two-temperature heat transfer in terms of a driving temperature difference, a functional relation between $\mathrm{Q}_{\mathrm{i}}$ and the three temperature differences, $\left\{\Delta \mathrm{T}_{\mathrm{ij}}\right\}$, is postulated. See Equation 5 wherein $\mathrm{Q}_{\mathrm{i}}$ is expressed as a linearized summation with $\Delta \mathrm{T}_{\mathrm{ij}}$ explicitly factored out of each term. Any nonlinearity with respect to $\left\{T_{i}\right\}$ is contained in $\left\{C_{i j}\right\}$.

$$
\mathrm{Q}_{\mathrm{i}}=\mathrm{Q}_{\mathrm{i}}\left(\left\{\Delta \mathrm{T}_{\mathrm{ij}}\right\}\right)=\sum_{\mathrm{j}} \mathrm{C}_{\mathrm{ij}}\left(\mathrm{T}_{\mathrm{i}}-\mathrm{T}_{\mathrm{j}}\right)
$$

The subscript $\mathrm{ij}$ is introduced to indicate that function $\mathrm{C}_{\mathrm{ij}}$ corresponds to the relation between a specific pair of temperatures: $T_{i}$ and $T_{j}$. Although it is anticipated, based on the two-temperature case, that $C_{i j}$ is constant for a given flow rate and constant fluid properties, no restriction on the form of $\mathrm{C}_{\mathrm{ij}}$ is assumed at this stage.

Equation 5 can be rewritten as Equation 6 where $C_{i j}$ is replaced by a new function: $R_{i j}=\frac{1}{C_{i j}}$.

$$
Q_{i}=\sum_{j} \frac{T_{i}-T_{j}}{R_{i j}}
$$


Equation 6 now resembles energy balances at the nodes of a thermal network such as the delta network shown in Figure 4. In Figure 4, each boundary temperature of the problem - an isothermal heat source/sink - is represented by a temperature node. To represent the fluid flow, the inlet temperature, $\mathrm{T}_{0}$, is chosen because it is the independent temperature associated with the fluid, as opposed to, say, $\mathrm{T}_{\mathrm{m}}$ which is a function of all the boundary temperatures.

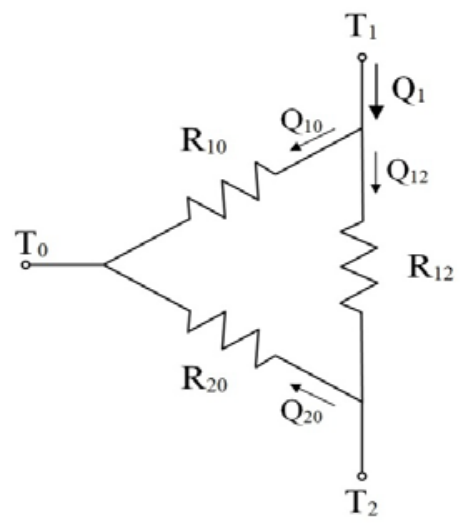

Fig. 4 Three-resistor thermal network of flow in asymmetrically-heated channel.

In connection to the thermal network of Figure 4, the functions $\mathrm{R}_{\mathrm{ij}}$ correspond to paired convective resistances that characterize the network. The term "paired” is used to emphasize that $\mathrm{R}_{\mathrm{ij}}$ corresponds to $\mathrm{Q}_{\mathrm{ij}}$, the heat transfer between a specific pair of nodes, $T_{i}$ and $T_{j}$. Heat transfer through each leg of the network can be written as shown in Equation 7.

$$
\mathrm{Q}_{\mathrm{ij}}=\frac{\mathrm{T}_{\mathrm{i}}-\mathrm{T}_{\mathrm{j}}}{\mathrm{R}_{\mathrm{ij}}} \quad \mathrm{i}=0,1,2 \quad \mathrm{j}=0,1,2 \quad \mathrm{i} \neq \mathrm{j}
$$

Applying Equation 6 to the node representing the fluid $(\mathrm{i}=0)$, for example, the total heat transfer to the fluid will be given as the sum of two wall-to-fluid components. Similarly, heat transfer from a wall will be the sum of wall-tofluid and wall-to-wall components.

If the set of convective resistances, $\left\{\mathrm{R}_{\mathrm{ij}}\right\}$, is known, heat transfer rate at the nodes, $\left\{\mathrm{Q}_{\mathrm{i}}\right\}$, can be calculated. Furthermore, the knowledge of $\left\{\mathrm{R}_{\mathrm{ij}}\right\}$ leads to a new insight: the split of heat transfer between the legs of the network, $\left\{Q_{i j}\right\}$, can now be resolved. Otherwise, the paired heat transfer components, $\left\{Q_{i j}\right\}$, remain unknown.

\footnotetext{
* This choice of reference temperature is not unusual. In the study of heat exchangers, for instance, the same approach is taken to assess the performance of the device based on a maximum heat transfer potential (temperature difference).
} 


\section{Solving for $\left\{R_{i j}\right\}$}

To evaluate the set of paired resistances, $\left\{\mathrm{R}_{\mathrm{ij}}\right\}$, first Equation 6 is applied at node $\mathrm{T}_{1}$. In connection to the network of Figure 4, this means the total heat transfer at this node, $Q_{1}$, is the sum of the heat transfer from $T_{1}$ to $T_{2}$, $\mathrm{Q}_{12}$, and the heat transfer from $\mathrm{T}_{1}$ to $\mathrm{T}_{0}, \mathrm{Q}_{10}$. See Equation 8 .

$$
\mathrm{Q}_{1}=\frac{\mathrm{T}_{1}-\mathrm{T}_{2}}{\mathrm{R}_{12}}+\frac{\mathrm{T}_{1}-\mathrm{T}_{0}}{\mathrm{R}_{10}}=\mathrm{Q}_{12}+\mathrm{Q}_{10}
$$

A similar relation is written for $\mathrm{Q}_{2}$, as shown in Equation 9 .

$$
\mathrm{Q}_{2}=\frac{\mathrm{T}_{2}-\mathrm{T}_{1}}{\mathrm{R}_{12}}+\frac{\mathrm{T}_{2}-\mathrm{T}_{0}}{\mathrm{R}_{20}}
$$

Equation 6 also can be applied at $\mathrm{T}_{0}$. With $\left\{\mathrm{R}_{\mathrm{ij}}\right\}$ unknown, these nodal energy balances form a system of three equations and three unknowns. But these equations cannot be solved for the unknowns, $\left\{\mathrm{R}_{\mathrm{ij}}\right\}$, because they are not independent; they are interconnected through the overall energy balance of the network: $\mathrm{Q}_{0}+\mathrm{Q}_{1}+\mathrm{Q}_{2}=0$.

An observation about the functional dependence of convective resistances needs to be made at this point. For a given geometry, the convective resistances, $\left\{R_{i j}\right\}$, will be each a function of the velocity field and fluid properties. Any dependence on temperature will be caused by the effects of temperature on the velocity field, e.g. buoyancy, or temperature-dependent fluid properties. With the fluid properties assumed to be constant and the velocity profile known to be symmetric about $y=0$, the two wall-to-fluid resistances must then be equal: $\mathrm{R}_{10}=\mathrm{R}_{20}$. This observation is crucial to the solution presented here.

With $\mathrm{R}_{10}=\mathrm{R}_{20}$, Equations 8 and 9 can now be summed and rearranged to obtain Equation $10 .^{\dagger}$

$$
\mathrm{R}_{10}=\mathrm{R}_{20}=\frac{\mathrm{T}_{1}+\mathrm{T}_{2}-2 \mathrm{~T}_{0}}{\mathrm{Q}_{1}+\mathrm{Q}_{2}}=2 \frac{\left(\mathrm{T}_{\mathrm{wm}}-\mathrm{T}_{0}\right)}{\mathrm{Q}_{1}+\mathrm{Q}_{2}}
$$

Next, Equation 9 is subtracted from Equation 8 to obtain $\mathrm{R}_{12}$. See Equation 11.

$$
\mathrm{R}_{12}=2\left[\left(\frac{\mathrm{Q}_{1}-\mathrm{Q}_{2}}{\mathrm{~T}_{1}-\mathrm{T}_{2}}\right)-\frac{1}{\mathrm{R}_{10}}\right]^{-1}=2\left[\frac{\mathrm{Q}_{1}-\mathrm{Q}_{2}}{\mathrm{~T}_{1}-\mathrm{T}_{2}}-\frac{\mathrm{Q}_{1}+\mathrm{Q}_{2}}{\mathrm{~T}_{1}+\mathrm{T}_{2}-2 \mathrm{~T}_{0}}\right]^{-1}
$$

Therefore, the resistances characterizing the thermal network of Figure 4 can be obtained for a set of imposed boundary temperatures if the heat transfer rates from the walls are known.

\footnotetext{
${ }^{\dagger}$ Note the difference between Equation 10 and the modified Nusselt number suggested by Nield [3]: instead of $\mathrm{T}_{\mathrm{m}}$, $\mathrm{T}_{0}$ is used as the fluid temperature. As discussed in Section IV, this difference turns out to be significant.
} 


\section{Paired Nusselt Numbers}

Hatton and Turton [1] obtained a series solution to Equation 2 in terms of the dimensionless temperature $\theta=\left(T-T_{w m}\right) /\left(T_{1}-T_{w m}\right)$, and in the form shown in Equation 12.

$$
\theta=\left(\frac{2 y}{H}\right)-\sum_{n=1}^{\infty} C_{n} f_{n} \exp \left(-\frac{8}{3} \lambda_{n}^{2} X\right)
$$

In Equation 12, the first term on RHS is the linear, fully-developed temperature profile, and the summation is the series solution to a Sturm-Liouville system, with $C_{n}, f_{n}$ and $\lambda_{n}$ denoting the coefficients, the eigenfunctions and the eigenvalues, respectively. $\mathrm{X}$ is the inverse Graetz number, defined in Equation 3.

With the temperature distribution known, heat flux at either wall is obtained as shown in Equation 13, where $\overline{\mathrm{y}}=2 \mathrm{y} / \mathrm{H}$ denotes dimensionless $\mathrm{y}$-coordinate.

$$
\begin{aligned}
\mathrm{q}_{\mathrm{i}} & =-\frac{\mathrm{k}}{\mathrm{H}}\left(\mathrm{T}_{1}-\mathrm{T}_{2}\right)\left(\frac{\partial \theta}{\partial \overline{\mathrm{y}}}\right)_{\overline{\mathrm{y}}_{\mathrm{i}}} \\
& =-\frac{\mathrm{k}}{\mathrm{H}}\left(\mathrm{T}_{1}-\mathrm{T}_{2}\right)\left[1-\sum_{\mathrm{n}=1}^{\infty} \mathrm{C}_{\mathrm{n}}\left(\frac{\mathrm{df_{ \textrm {n } }}}{\mathrm{d} \overline{\mathrm{y}}}\right)_{\overline{\mathrm{y}}_{\mathrm{i}}} \exp \left(-\frac{8}{3} \lambda_{\mathrm{n}}^{2} \mathrm{X}\right)\right]
\end{aligned}
$$

Heat fluxes are then integrated from the channel entrance to any location $\mathrm{x}$, to find the total heat transfer rates, $\mathrm{Q}_{1}$ and $\mathrm{Q}_{2}$. See Equation 14 .

$$
\begin{aligned}
\mathrm{Q}_{\mathrm{i}} & =\int_{0}^{\mathrm{x}} \mathrm{q}_{\mathrm{i}} \mathrm{dx} \\
& =-\frac{\mathrm{k}}{\mathrm{H}}\left(\mathrm{T}_{1}-\mathrm{T}_{2}\right) \int_{0}^{\mathrm{x}}\left[1-\sum_{\mathrm{n}=1}^{\infty} \mathrm{C}_{\mathrm{n}}\left(\frac{\mathrm{df}}{\mathrm{dy}}\right)_{\bar{y}_{\mathrm{i}}} \exp \left(-\frac{8}{3} \lambda_{\mathrm{n}}^{2} \mathrm{X}\right)\right] \mathrm{dx}
\end{aligned}
$$

The summation can be integrated as shown in Equation 15.

$$
\begin{aligned}
\int\left[\sum_{n=1}^{\infty} C_{n}\left(\frac{d f_{n}}{d \bar{y}}\right)_{y_{i}} \exp \left(-\frac{8}{3} \lambda_{n}^{2} X\right)\right] d x \\
=\operatorname{Re} \cdot \operatorname{Pr}\left(\frac{H}{2}\right) \sum_{n=1}^{\infty}\left\{C_{n}\left(\frac{d f_{n}}{d \bar{y}}\right) \int \exp \left(-\frac{8}{3} \lambda_{n}^{2} X\right) d X\right\} \\
=\operatorname{Re} \cdot \operatorname{Pr}\left(\frac{H}{2}\right) \sum_{n=1}^{\infty}\left\{-\frac{3 C_{n}}{8 \lambda_{n}^{2}}\left(\frac{d f_{n}}{d \bar{y}}\right) \exp \left(-\frac{8}{3} \lambda_{n}^{2} X\right)\right\}
\end{aligned}
$$


Finally, Equations 10 and 11 are used to obtain $\left\{\mathrm{R}_{\mathrm{ij}}\right\}$. To report the results in dimensionless form, average paired Nusselt numbers, $\left\{\overline{\mathrm{Nu}_{\mathrm{ij}}}\right\}$, are defined as shown in Equation 16.

$$
\mathrm{Q}_{\mathrm{ij}}=\frac{\left(\mathrm{T}_{\mathrm{i}}-\mathrm{T}_{\mathrm{j}}\right)}{\mathrm{R}_{\mathrm{ij}}}=\overline{\mathrm{Nu}_{\mathrm{ij}}} \frac{\mathrm{k}}{\mathrm{H}} \times\left(\mathrm{T}_{\mathrm{i}}-\mathrm{T}_{\mathrm{j}}\right) \quad \mathrm{i}=1,2 \quad \mathrm{j}=0,1,2 \quad \mathrm{i} \neq \mathrm{j}
$$

Equations 17 and 18 are the expressions obtained for $\left\{\overline{\mathrm{Nu}_{\mathrm{ij}}}\right\}$, using the eigenvalues and eigenfunctions reported by Hatton and Turton [1]. ${ }^{\ddagger}$

$$
\begin{aligned}
& \overline{\mathrm{Nu}_{12}}=\frac{1}{\mathrm{X}}\left(\mathrm{X}-0.2+0.2276 \mathrm{e}^{-7.54 \mathrm{X}}\right. \\
& -0.0367 \mathrm{e}^{-35.96 \mathrm{X}}-0.0133 \mathrm{e}^{-85.73 \mathrm{X}}-0.0066 \mathrm{e}^{-156.83 \mathrm{X}} \\
& +0.0038 \mathrm{e}^{-249.27 \mathrm{X}}-0.0025 \mathrm{e}^{-363.04 \mathrm{X}}+0.0017 \mathrm{e}^{-498.15 \mathrm{X}} \\
& -0.0012 \mathrm{e}^{-654.59 \mathrm{X}}+0.0009 \mathrm{e}^{-832.39 \mathrm{X}}-0.0001 \mathrm{e}^{-1031.47 \mathrm{X}} \\
& +0.0006 \mathrm{e}^{-1251.93 \mathrm{X}}-0.0005 \mathrm{e}^{-1493.69 \mathrm{X}}+0.0004 \mathrm{e}^{-1756.80 \mathrm{X}} \\
& \left.-0.0003 \mathrm{e}^{-2041.25 \mathrm{X}}+0.0003 \mathrm{e}^{-2347.03 \mathrm{X}}-0.0002 \mathrm{e}^{-2674.81 \mathrm{X}}\right) \\
& \overline{\mathrm{Nu}_{10}}=\overline{\mathrm{Nu}_{20}}=\frac{1}{\mathrm{X}}\left(0.5-0.4552 \mathrm{e}^{-7.54 \mathrm{X}}-0.0266 \mathrm{e}^{-85.73 \mathrm{X}}\right. \\
& -0.0076 \mathrm{e}^{-249.27 \mathrm{X}}-0.0034 \mathrm{e}^{-498.15 \mathrm{X}}-0.0019 \mathrm{e}^{-832.39 \mathrm{X}} \\
& \left.-0.0012 \mathrm{e}^{-1251.93 \mathrm{X}}-0.0008 \mathrm{e}^{-1756.80 \mathrm{X}}-0.0006 \mathrm{e}^{-2347.03 \mathrm{X}}\right)
\end{aligned}
$$

As expected, no dependence on $\left\{\mathrm{T}_{\mathrm{i}}\right\}$ or $\mathrm{r}_{\mathrm{T}}$ is observed. The paired Nusselt numbers depend only on $\mathrm{X}$, i.e. a combination of geometry, flow rate and fluid properties. The obtained $\left\{\overline{\mathrm{Nu}_{\mathrm{ij}}}\right\}$ can be used for any $\left\{\mathrm{T}_{\mathrm{i}}\right\}$, including the two-temperature case. In Figure 5, the above expressions for $\overline{\mathrm{Nu}_{10}}$ and $\overline{\mathrm{Nu}_{12}}$ as well as approximations obtained by keeping the first exponential terms only are plotted versus X. It can be seen that the first-exponent approximation to $\overline{\mathrm{Nu}_{12}}$ shows significant deviation from Equation 17 for $\mathrm{X} \lesssim 0.1$, but very close agreement for $\mathrm{X}>0.1$. The one-exponent approximation to $\overline{\mathrm{Nu}_{10}}$ replicates Equation 18 for essentially all $\mathrm{X}>0$. To demonstrate the utility of these results, the calculation of paired and total heat transfer rates using $\left\{\overline{\mathrm{Nu}_{\mathrm{ij}}}\right\}$ for a sample case is presented in the Appendix.

\footnotetext{
${ }^{\ddagger}$ Noting that $\mathrm{q}_{\mathrm{i}}$ has an integrable singularity at $\mathrm{X}=0$, the lower limit of the integral of Equation 14 was adjusted to $10^{-4}$.
} 


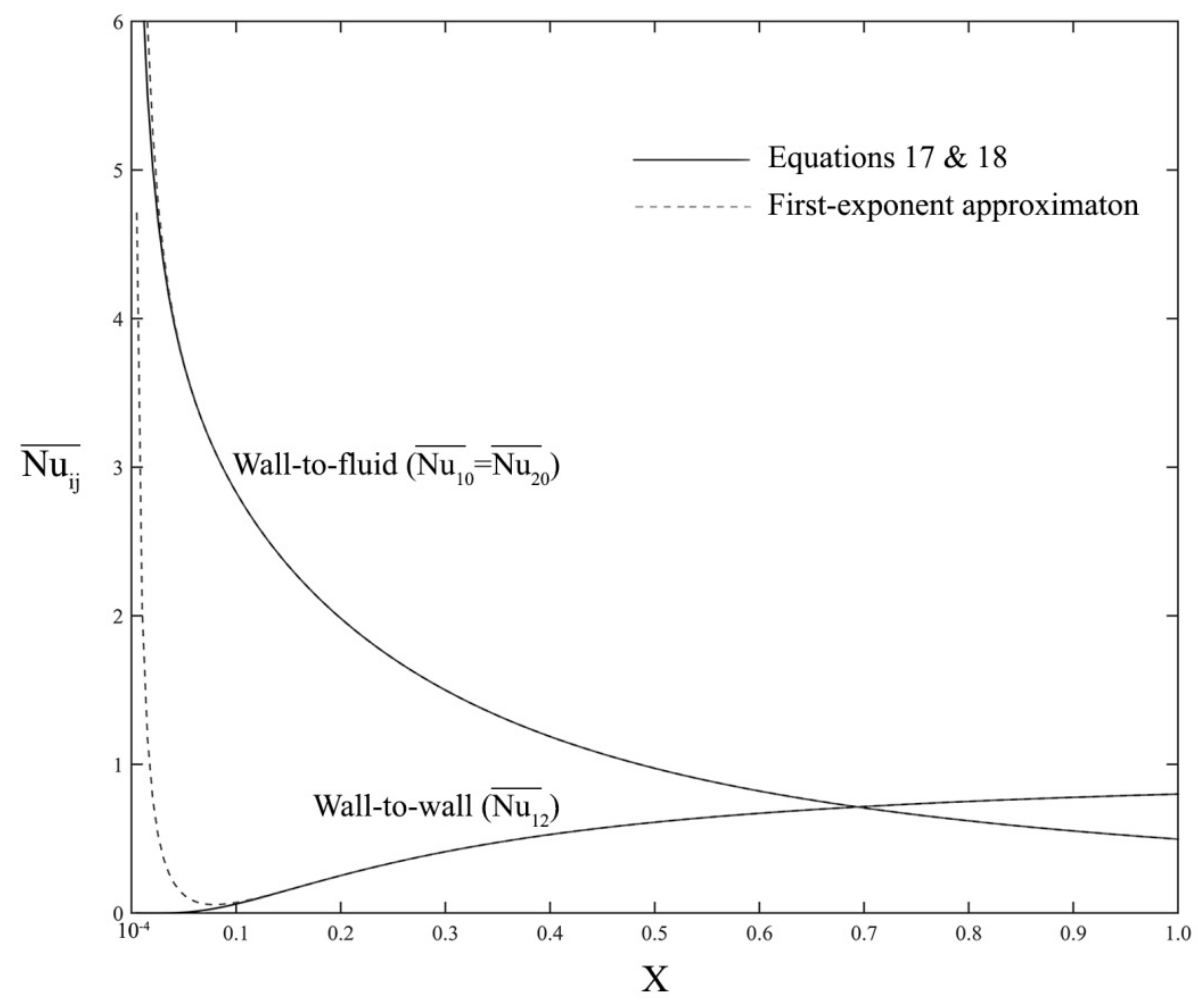

Fig. 5 Distribution of average paired Nusselt Numbers $\left(\overline{\mathrm{Nu}_{\mathrm{ij}}}\right)$.

\section{Local Paired Nusselt Numbers}

To make direct comparison with the local Nusselt numbers reported by Hatton and Turton (Figure 3) possible, a local paired Nusselt number, $\mathrm{Nu}_{\mathrm{ij}}$, may also be defined based on the wall heat flux at location $\mathrm{x}$ such that $\mathrm{Nu}_{\mathrm{ij}}$ corresponds to $\mathrm{q}_{\mathrm{ij}}$, the component of $\mathrm{q}_{\mathrm{i}}$ driven by $\left(\mathrm{T}_{\mathrm{i}}-\mathrm{T}_{\mathrm{j}}\right)$. Equation 19 provides the definition.

$$
\mathrm{q}_{\mathrm{ij}}=\mathrm{Nu}_{\mathrm{ij}} \frac{\mathrm{k}}{\mathrm{H}}\left(\mathrm{T}_{\mathrm{i}}-\mathrm{T}_{\mathrm{j}}\right) \quad \mathrm{i}=1,2 \quad \mathrm{j}=0,1,2 \quad \mathrm{i} \neq \mathrm{j}
$$

The heat flux, $\mathrm{q}_{\mathrm{ij}}$, can be evaluated using Equation 20.

$$
\mathrm{q}_{\mathrm{ij}}=\frac{\partial \mathrm{Q}_{\mathrm{ij}}}{\partial \mathrm{x}}=\frac{\mathrm{k}}{\mathrm{H}}\left(\mathrm{T}_{\mathrm{i}}-\mathrm{T}_{\mathrm{j}}\right) \frac{\mathrm{d}}{\mathrm{dx}}\left(\overline{\mathrm{Nu}_{\mathrm{ij}} \mathrm{x}}\right)
$$

Combining Equations 19 and 20, a relation between the local and average paired Nusselt numbers is obtained. See Equation 21.

$$
\mathrm{Nu}_{\mathrm{ij}}=\frac{\mathrm{d}}{\mathrm{dX}}\left(\overline{\mathrm{Nu}_{\mathrm{ij}}} \mathrm{X}\right)
$$


The local paired Nusselt numbers are plotted in Figure 6. The temperature profiles of Figure 2 may be used to gain insight into these results. Near the inlet there is a core of fluid flowing at $T_{0}$ which is not affected by heat transfer from the walls. Downstream where the boundary layers merge, this core vanishes and the temperature profile eventually evolves into a linear profile which is independent of the inlet conditions. Accordingly, $\mathrm{Nu}_{10}$ starts from infinity at the inlet, similar to forced convection over a flat plate. Moving downstream wall-to-fluid heat transfer decays to zero in the thermally-developed limit. Accordingly, $\mathrm{Nu}_{10} \approx 0$ for $\mathrm{X} \gtrsim 0.7$. The variation of $\mathrm{Nu}_{12}$ along the channel follows a different trend: at the entrance region, where there is enhanced heat transfer between the walls and the fluid, the walls do not "communicate" thermally; $\mathrm{Nu}_{12} \approx 0$ for $0 \leq \mathrm{X} \leq 0.05$. For $\mathrm{X}>0.05$, as the two thermal boundary layers become thicker, $\mathrm{Nu}_{12}$ increases, approaching the pure-condition limit of $\mathrm{Nu}_{12}=1$.

The two curves shown in Figure 6 can be used to replace the entire family of $\mathrm{r}_{\mathrm{T}}$-dependent curves shown in Figure 3. In comparison with Figure 3, the curves of Figure 6 are also a better presentation of the thermal development of the flow. It can be seen that the thermal development length is a function of X only; regardless of $r_{\mathrm{T}}$, the flow reaches thermal development essentially by $\mathrm{X} \approx 0.7$.

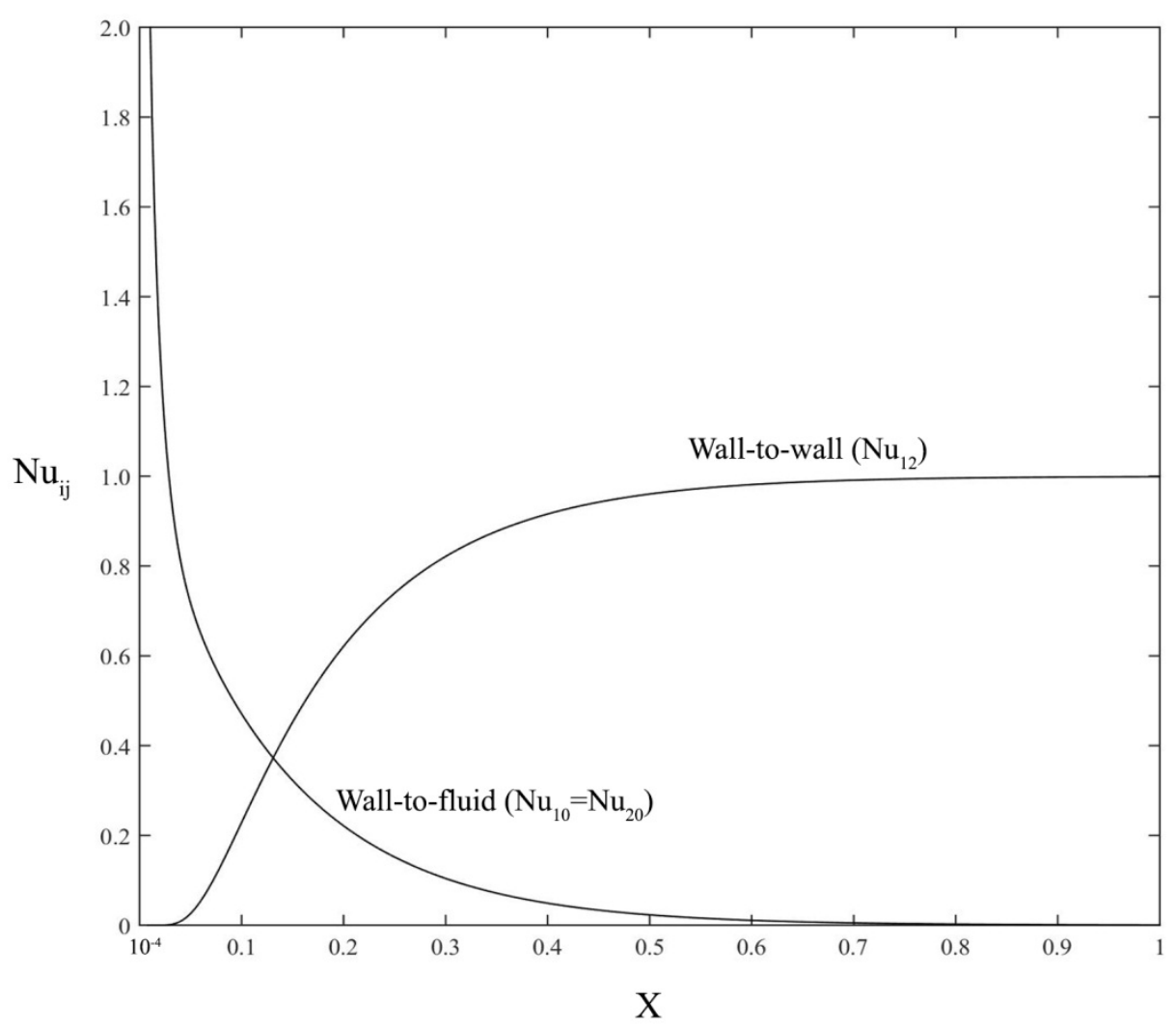

Fig. 6 Distribution of local paired Nusselt Numbers $\left(\mathrm{Nu}_{\mathrm{ij}}\right)$. 


\section{Summary of Findings}

In summary, the characterization of the asymmetric Graetz problem, a three-temperature convection problem, in terms of a delta thermal-resistor network leads to several advantages:

- A more complete picture emerges; the split of heat transfer between the different temperature nodes can now be resolved using the paired Nusselt numbers.

- The extra singularities observed in the classical solution (Figure 3) are eliminated.

- The trends are more consistent with the physics of the problem: the wall-to-wall Nusselt numbers start from zero at the entrance and approach the pure-conduction limit as $\mathrm{X} \rightarrow \infty$, while the wall-to-fluid Nusselt number starts from infinity at the inlet and smoothly decays to zero in the thermally development limit.

- The paired Nusselt numbers are independent of temperature ratio (and temperature).

- Two universal Nusselt-number distributions are obtained that can be applied to any fluid, any laminar flow rate and any temperature ratio.

\section{Conclusion}

The classical problem of heat transfer to laminar hydrodynamically-developed flow in an asymmetrically-heated channel, the asymmetric Graetz problem, was investigated in a resistor-network framework. It was shown that the problem can be represented by a delta network entailing three thermal resistors. Due to symmetry, the two wall-tofluid resistances are equal, reducing the number of the unknowns to two and making the system of equations resulting from nodal energy balances solvable. Using a previous analysis from the literature, analytical expressions were obtained for the wall-to-wall and wall-to-fluid resistances. Formulating this problem in terms of a thermalresistor network has several advantages. Notably, the singularities observed in a previous solution have been eliminated, and Nusselt numbers were obtained which are independent of temperature ratio. Moreover, the split of heat transfer between different temperature nodes can now be resolved using the proposed paired Nusselt numbers. As demonstrated in the Appendix, the heat transfer rate from either channel wall can be resolved into wall-to-fluid component and wall-to-wall components. This is new information that provides insight into the physics of the problem.

The resistor-network formulation presented in this work applies to steady-state convection problems involving isothermal boundaries only. To extend this approach to problems with isoflux boundaries, an approximation needs 
be introduced: the isoflux boundary must be approximated as isothermal (segments) at some average temperature. This approximation is conventionally used in convection heat transfer to utilize correlations developed for isothermal conditions for problems involving isoflux boundaries. Moreover, the symmetry observed between the two wall-to-fluid resistances was key in reducing the number of unknowns and evaluating the paired resistances. Nevertheless, in formulating the three-temperature problem in terms of a resistor network, no assumptions were made regarding the nature of the flow. The resistor-network approach, which provides a compact presentation of the results, is hence applicable even if the flow is hydrodynamically developing; if the fluid properties are not constant; or if the flow is turbulent. The evaluation of the resistances will however be more complicated. The more general case where symmetry cannot be invoked, i.e. when the two wall-to-fluid resistances are not equal, as well as the extension of the resistor-network approach to the generic problem of multi-temperature convection will be presented in future works. In extending the methodology, the analytical results presented in this paper will be used to validate a generic technique for evaluating paired resistances of complex multi-temperature convection problems.

\section{Appendix: Calculating $\left\{Q_{i}\right\}$ and $\left\{Q_{i j}\right\}$ using $\left\{\overline{N_{i j}}\right\}$}

Consider a flow of water at $\dot{\mathrm{m}}=0.048 \frac{\mathrm{kg}}{\mathrm{s} \cdot \mathrm{m}}$ and $\mathrm{T}_{0}=10^{\circ} \mathrm{C}(\mathrm{Re}=100, \mathrm{Pr}=6.7)$, in a microchannel with $\mathrm{H}=60 \mu \mathrm{m}$ and $\mathrm{T}_{1}=20^{\circ} \mathrm{C}, \mathrm{T}_{2}=30^{\circ} \mathrm{C}$. The heat transfer performance of the microchannel from the entrance $(\mathrm{x}=0)$ to some location (length), say $x=3 \mathrm{~mm}$, is of interest.

The rate of total heat transfer to fluid (from both walls) per unit channel width, $\mathrm{Q}_{0}$, can be calculated using an overall energy balance:

$$
\mathrm{Q}_{0}=\rho \mathrm{u}_{\mathrm{m}} \mathrm{HC}_{\mathrm{p}}\left[\mathrm{T}_{0}-\mathrm{T}_{\mathrm{m}}(\mathrm{x})\right]
$$

The mean fluid temperature is known from the solution by Hatton and Turton [1]:

$$
\begin{aligned}
& \mathrm{T}_{\mathrm{m}}=\mathrm{T}_{\mathrm{wm}}+\frac{3}{2}\left(\mathrm{~T}_{1}-\mathrm{T}_{2}\right)\left(0.3034 \mathrm{e}^{-7.54 \mathrm{X}}+0.0177 \mathrm{e}^{-85.73 \mathrm{X}}\right. \\
& +0.0051 \mathrm{e}^{-249.27 \mathrm{X}}+0.0023 \mathrm{e}^{-498.15 \mathrm{X}}+0.0012 \mathrm{e}^{-832.39 \mathrm{X}} \\
& \left.+0.0008 \mathrm{e}^{-1251.93 \mathrm{X}}+0.0005 \mathrm{e}^{-1756.80 \mathrm{X}}+0.0004 \mathrm{e}^{-2347.03 \mathrm{X}}\right)
\end{aligned}
$$

The inverse Graetz number at $\mathrm{x}=3 \mathrm{~mm}$ is:

$$
\mathrm{X}=\frac{\mathrm{X}}{\mathrm{H} / 2} \cdot \frac{1}{\operatorname{Re} \operatorname{Pr}}=\frac{0.003}{3 \times 10^{-5}}\left(\frac{1}{100}\right)\left(\frac{1}{6.7}\right) \approx 0.15
$$


which leads to $\mathrm{T}_{\mathrm{m}}=20.58^{\circ} \mathrm{C}$. Therefore, with $\mathrm{C}_{\mathrm{p}}=4.182 \mathrm{~kJ} / \mathrm{kgK}$, the energy balance leads to:

$$
\mathrm{Q}_{0}=(0.048)(4182)(10-20.58)=-2123.8 \frac{\mathrm{W}}{\mathrm{m}}
$$

Heat transfer at each wall can be obtained using the Nusselt numbers given by Hatton and Turton [1], and evaluating the integral of Equation 12 between $x=0$ and $x=0.003 m$ :

$$
\begin{aligned}
& \mathrm{Q}_{1}=\int_{0}^{0.003} \mathrm{q}_{1} \mathrm{dx}=\frac{\mathrm{k}}{2} \operatorname{Re} \cdot \operatorname{Pr}\left(\mathrm{T}_{2}-\mathrm{T}_{1}\right) \int_{0}^{0.15} \mathrm{Nu}_{1}\left(\frac{1-\theta_{\mathrm{m}}}{4}\right) \mathrm{dX}=656.8 \frac{\mathrm{W}}{\mathrm{m}} \\
& \mathrm{Q}_{2}=\int_{0}^{0.003} \mathrm{q}_{2} \mathrm{dx}=\frac{\mathrm{k}}{2} \operatorname{Re} \cdot \operatorname{Pr}\left(\mathrm{T}_{1}-\mathrm{T}_{2}\right) \int_{0}^{0.15} \mathrm{Nu}_{2}\left(\frac{1+\theta_{\mathrm{m}}}{4}\right) \mathrm{dX}=1450.0 \frac{\mathrm{W}}{\mathrm{m}}
\end{aligned}
$$

In the equations above, $\mathrm{k}=0.6 \mathrm{~W} / \mathrm{mK}$ and $\theta_{\mathrm{m}}=\left(\mathrm{T}_{\mathrm{m}}-\mathrm{T}_{\mathrm{wm}}\right) /\left(\mathrm{T}_{1}-\mathrm{T}_{\mathrm{wm}}\right)$. Note that $\left\{\mathrm{Nu}_{\mathrm{i}}\right\}$ and $\theta_{\mathrm{m}}$ are both function of $r_{T}$. Therefore, the task of evaluating these integrals must be repeated for every new $r_{T}$. Furthermore, the split of heat transfer between the walls and the fluid, $\left\{\mathrm{Q}_{\mathrm{ij}}\right\}$, remains unknown.

With the wall heat transfer rates known, the total heat transfer rate to the fluid can also be calculated as:

$$
\mathrm{Q}_{0}=-\left(\mathrm{Q}_{1}+\mathrm{Q}_{2}\right)=-2106.8 \frac{\mathrm{W}}{\mathrm{m}}
$$

Alternatively, the paired Nusselt numbers may be used to calculate $\left\{Q_{i j}\right\}$ and $\left\{Q_{i}\right\}$. Substituting $X=0.15$ in Equations 17 and 18 (or from Figure 5), $\overline{\mathrm{Nu}_{10}}=\overline{\mathrm{Nu}_{20}}=2.34$ and $\overline{\mathrm{Nu}_{12}}=0.15$. Note that these values can be used for any $\mathrm{r}_{\mathrm{T}}$. Equation 13 thus gives:

$$
\begin{aligned}
\mathrm{Q}_{10} & =\overline{\mathrm{Nu}_{10}} \frac{\mathrm{k}}{\mathrm{H}} \times\left(\mathrm{T}_{1}-\mathrm{T}_{0}\right)=701.5 \frac{\mathrm{W}}{\mathrm{m}} \\
\mathrm{Q}_{20} & =\overline{\mathrm{Nu}_{20}} \frac{\mathrm{k}}{\mathrm{H}} \times\left(\mathrm{T}_{2}-\mathrm{T}_{0}\right)=1403.0 \frac{\mathrm{W}}{\mathrm{m}} \\
\mathrm{Q}_{12} & =\overline{\mathrm{Nu}_{12}} \frac{\mathrm{k}}{\mathrm{H}} \times\left(\mathrm{T}_{1}-\mathrm{T}_{2}\right)=-46.3 \frac{\mathrm{W}}{\mathrm{m}}
\end{aligned}
$$

Further note that $\left\{\mathrm{Q}_{\mathrm{ij}}\right\}$ can only be calculated with the knowledge of $\left\{\mathrm{R}_{\mathrm{ij}}\right\}$.

Then, nodal energy balances lead to:

$$
\begin{gathered}
\mathrm{Q}_{0}=\mathrm{Q}_{10}+\mathrm{Q}_{20}=-2104.5 \frac{\mathrm{W}}{\mathrm{m}} \\
\mathrm{Q}_{1}=\mathrm{Q}_{10}+\mathrm{Q}_{12}=655.2 \frac{\mathrm{W}}{\mathrm{m}}
\end{gathered}
$$




$$
\mathrm{Q}_{2}=\mathrm{Q}_{20}+\mathrm{Q}_{21}=1449.3 \frac{\mathrm{W}}{\mathrm{m}}
$$

Using the first-exponent approximations to Equations 17 and 18, a simple expression for $\mathrm{Q}_{0}$ may be obtained:

$$
\begin{aligned}
\mathrm{Q}_{0}(\mathrm{x})=\overline{\mathrm{Nu}_{10}} \frac{\mathrm{k}}{\mathrm{H}} \mathrm{x}\left(2 \mathrm{~T}_{0}-\mathrm{T}_{1}-\mathrm{T}_{2}\right) & =\operatorname{Re} \operatorname{Pr}\left(0.5-0.4552 \mathrm{e}^{-7.54 \mathrm{X}}\right) \frac{\mathrm{k}}{2}\left(2 \mathrm{~T}_{0}-\mathrm{T}_{1}-\mathrm{T}_{2}\right) \\
& =\operatorname{Re} \operatorname{Pr}\left(0.5-0.4552 \mathrm{e}^{-7.54 \mathrm{X}}\right) \mathrm{k}\left(\mathrm{T}_{0}-\mathrm{T}_{\mathrm{wm}}\right)
\end{aligned}
$$

This expression could also be obtained using the overall energy balance and the one-term approximation for $\mathrm{T}_{\mathrm{m}}$.

\section{Acknowledgements}

The authors acknowledge the financial support of the Smart Net-Zero Energy Buildings Strategic Research Network (SNEBRN) of the Natural Sciences and Engineering Research Council of Canada (NSERC) and the University of Waterloo.

\section{References}

[1] Hatton, A.P., and Turton, J.S.., "Heat Transfer in The Thermal Entry Length with Laminar Flow Between Parallel Walls at Unequal Temperatures,” Intl. J. Heat Mass Transfer, Vol. 5, No.7, 1962, pp. 673, 679.

[2] Mitrović, J., Maletić. B., and Bačlić, B.S., “Some Peculiarities of the Asymmetric Graetz Problem,” Intl. J. Eng. Science, Vol. 44, No. 7, 2006, pp. 436, 455.

doi: 10.1016/j.ijengsci.2006.02.003

[3] Nield, D.A., “Forced Convection in a Parallel Plate Channel with Asymmetric Heating,” Intl. J. Heat Mass Transfer, Vo. 47, No. 25, 2004, pp. 5609, 5612.

doi: 10.1016/j.ijheatmasstransfer.2004.07.006

[4] Wright, J.L., Barnaby, C.S., Niles, P., and Rogalsky, C.J., "Efficient Simulation of Complex Fenestration Systems in Heat Balance Room Models,” 12th International Conference of the International Building Performance Simulation Association, Sydney, Australia, 2011, pp. 2851, 2858.

[5] Barnaby, C.S., Wright, J.L., and Collins, M.R., “Improving Load Calculations for Fenestration with Shading Devices,” ASHRAE Transactions, Vol. 115, Part 2, 2009, pp. 31, 44.

[6] Foroushani, S.S.M., Wright, J.L., Naylor, D., and Collins, M.R., “Assessing Convective Heat Transfer Coefficients Associated with Indoor Shading Attachments Using a New Technique Based on Computational Fluid Dynamics,” ASHRAE Winter Conference, Chicago, Il, 2015, Paper\#CH-15-C046, 8 pages. 